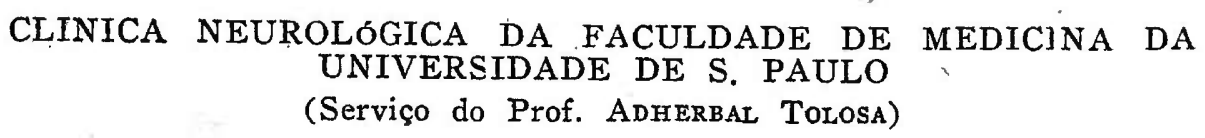

\title{
CONSIDERAÇÕES EM TORNO DE UM CASO DE HEMATOMIELIA $(*)$
}

\author{
JOÃO A. CAETANO DA SILVA JUNIOR \\ Assistente voluntário
}

O caso que passaremos a relatar pareceu-nos sobremodo interessante, justificando assim a sua publicação, pela discordancia verificada entre os resultados de dois exames neurológicos de que foi objéto, ó primeiro realizado em 1934 e o outro em Março de 1941.

Como resultado dessa discordância entre os dois exames realizados chegou-se em ambos a um diagnóstico diferente: no primeiro foi diagnosticada uma "esclerose lateral amiotrófica, de forma hemiplégica, apopletiforme", emquanto que, no segundo, chegou-se a conclusão de tratar-se de uma "hematomielia espontânea localizada na hemimedula esquerda, entre os segmentos C6 e D1".

Os principais fátos que nos levaram a fazer este último diagnóstico foram em primeiro lugar a parada da evolução de alguns dos sintomas que já se apresentavam no primeiro exame, assim como a existencia de alguns outros que não encontramos assinalados no mes-" mo e, alem disso pela interpretação diversa dada a alguns dos sintomas apreciados em conjunto que, por ocasião daquele exame foram considerados isoladamente.

Passemos agora á observação do doente em apreço, após o que faremos algumas breves considerações a respeito do caso.

\section{OBSERVAC̨ÁO NEUROLOGICA}

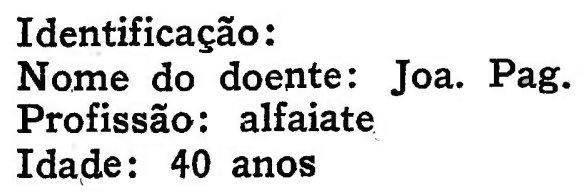

Procedendia: Capital Nacionalidade: brasileiro Côr: branco Estado civil: solteiro

Antecedentes familiares - Os pais sempre tiveram bôa saude emquanto vivos. O pai faleceu de nefrite. Mãe falecida após congestão pulmonar. Não conhece na família casos de moléstia nervosa, mesmo em parentes mais afastados. Tem cinco irmãos, todos sãos.

(*) Trabalho apresentado no II. Cóngresso Médico-Estudantino de S. Paulo, realizado em Setembro de 1941. 
Antecedentes pessoais - Sempre teve bôa saude, embora a perturbação neurologica que apresenta e que será descrita mais adiante já date de 30 anos. Refere que aos 4 ou 5 anos teve perturbações intestinais. Das moléstias peculiares á infancia refere apenas o sarampo. Nega contágio venéreofluético. Hábitos: alimenta'ção variada, comendo de tudo e nada lhe fazendo mal. Fuma cerca de meio maço de cigarros por dia. Bebe raras vezes e, quando o faz, em pequena quantidade.

História da moléstia átual - Aos 10 anos de idade, em 1910, quando estava servindo á mesa, pois já trabalhava em serviços domésticos, sentiu repentinamente um calefrio e uma fraqueza generaralizada, caindo ao solo. Ficou completamente impossibilitado de realizar qualquer movimento. Não perdeu a conciência, mantendo-se lúcico; falava, via e ouvia perfeitamente. Não havia perturbações esfincterianas. Foi levado ao leito e dois dias depois removido para a Santa Casa de Misericórdia, sendo internado na $3 .^{\mathrm{a}} \mathrm{M}$. H., completamente paralítico dos membros superiores e inferiores. Não tinha dôres, nem formigamentos, nem quaesquer perturbações sensitivas.

Cinco ou seis mezes depois de sua internação, comeparam a reaparecer os movimentos, de início nos membros superiores, depois nos inferiores, após or que, poude iniciar alguns passos e logo andar. No início, a marcha realizava-se apoiando-se aos leitos porem, aos poucos, poude realizá-la sosinhọ. Nunca teve febre durante o período de internação.

Quando se iniciou a recuperação funcional, percebeu que a mesma se fazia incompletamente na mão esquerda.

Infelizmente não nos foi possivel obter uma ficha em que estivessem indicações referentes a sua doença nessa época, ou porque ainda não houvesse um fichário na ocasião (1910), ou porque o mesmo se tenha extraviado.

Depois de um ano de intèrnação teve alta, apresentando-se já nessa ocasião nas mesmas condições em que se acha atualmente, isto é, com os membros do hemicorpo esquerdo mais delgados e menos habeis que os do lado direito.

A' medida que crescia, notava que essa diferença entre um lado e o outro do corpo se tornava mais nitida.

Depois de dois anos do início da moléstia, fez tratamento fisioterápico, que consistiu em correntes galvânicas e massagens durante algum tempo, porem não obteve melhora alguma.

Continuou nessa mesma situação daí por diante, pođendo trabalhar relativamente bem, tanto que aprendeu e ainda exerce o ofício de alfaiate.

Devemos notar que essas informações que o doente nos prestou, baseiam-se em pequena parte no que se lembra do sucedido, sendo que a maior parte dos detalhes lhe foi contada pelos parentes especialmente pela mãe, que já é falecida.

Em 1934, como sentisse nervosismo, mal estar e insonia persistente dirigiu-se ao Hospital Umperto I. ${ }^{\circ}$ Apresentava tambem nessa 
época, dificuldade na emissão de urinas, que o obrigava a esperar alguns minutos para que a micção se iniciasse. Até hoje apresenta certa dificuldade na micção.

Ná consulta que fez no Hospital Umberto I. ${ }^{\circ}$, disseram-lhe que as perturbações que apresentava nada tinham a vêr com a doença anterior. Feito nessa ocasião o exame do sangue no sentido de se verificar a existencia de sífilis, a reação de WASSERMANN foi positiva no 3..$^{\circ}$ exame realizado. Devido a isso, iniciou tratamento anti-luético, tendo sido aplicadas durante 7 a 8 meses, injeções de Néo-salvarsan. Depois dessa medicação, um novo exame do sangue mostrou um resultado negativo.

Ainda nessa ocasião, o médico que o atendeu recomendou-lhe fazer aplicações de radioterapia profunda para melhorar a paralisia da mão esquerda. Dirigiu-se então á Santa Casa, tendo sido internado na $1 .^{\mathrm{a}} \mathrm{M}$. H.

Foi feito aí um exame neurológico, cujo resultado foi o seguinte (ficha Hn-26 - Registro S. N. - 2.802) :

"1 - Marcha ceifante, com quéda do pé do lado esquerdo.

2. - Fenômenos amiotróficos do mesmo lado, desde o território do facial até os mesmos inferiores, porem mais acentuados no antebraço e mão esquerdos, onde revestem o tipo Aran-Duchenne, com desaparecimento das eminências tenar e hipotenar e consequente mão simiesca; impossibilidade da execução dos tests de Froment e GarDÈRE para o mediano; grande atrofia dos musculos do antebraço de inervação do mediano; tremores fibrilares intensos ao nivel da cintura escapular. A atrofia manifesta-se tambem na face, onde os traços são caidos - face "pleurard" dos francezes, encontrando-se como consequencia a diminuição da rima palpebral. Diminuição da força muscular á esquerda.

3 - Sinais de piramidalismo á esquerda. Marcha espástica; hipertonia acentuada no membro inferior esquerdo. Exagero dos reflexos tendinosos inferiores esquerdos, com clonus da rótula e pé correspondentes. Reflexo contralateral de Pierre-Marie; reflexo medio-pubiano exaltado. Exagero dos reflexos tendinosós superiores, que são facilmente obtidos, inclusive o do omoplata (sinal de Neri). Reflexo masseterino vivo. Reflexos abdominais cutaneos e cremasterinos muito diminuidos do lado esquerdo. Reflexo cutaneo-plantar presente do lado direito e invertido do lado esquerdo: sinal de $\mathrm{BA}$ BINSKI em leque. A' esquerda observamos aindà os sinais de Ros.SOLIMO e MENDEL-BeCHTEREW.

4 - Ausencia de distúrbios da sensibilidade e dos esfincteres. Anisocoria. Pupila direita maior que a esquerda. Reflexos pupilares normais.

5 - Reação de degeneração parcial dos musculos das eminencias tenar e hipotenar esquerdas.

6 - Síndromo humoral raqueano negativo bem como os exames de sangue e de fezes.

Diagnóstico: Esclerose lateral amiotrófica - forma hemiplégic a, apopletiforme. 
Tratamento: radioterapia profunda da medula.

Exame do liquor: normal.

Exame elétrico dos nervos e dos músculos.

Membros inferiores: Ligeira hipoexcitabilidade galvânica nos musculos da região anterior da coxa e da pantorrilha do lado esquerdo. Nos músculos da face não encontramos perturbação da excitabilidade dos músculos do lado direito, ao passo que no lado esquerdo ha hipoexcitabilidade, no entanto todos os pontos reagem em intensidade abaixo de 10 MA.

Conclusão: Reação de degeneração dos diferentes grupos musculares do membro superior esquerdo de distribuição atípica (caráter poliomietítiço) "

Esteve internado 10 dias, depois do que obteve alta, iniciando logo a terapêutica radioterápica sobre a coluna vertebral, a qual realizou no Instituto de Radium "Arnaldo Vieira de Carvalho"

Fez sete séries de aplicações, desde Setembro de 1936, até Janeiro de 1941.

Depois desse tratamento seu estado em nada se alterou dirigindo-se então, a conselho médico, ao Ambulatório de Neurologia onde sęria estudada a possibilidade de ser feito novo tratamento.

Foi nessa ocasião que o recebemos para observar.

Inspeção geral do. doente - Aspéto geral bom. Indivíduo branco, magro, pele seca, cabelos e olhos castanhos. Panículo adiposo escasso. Musculatura - vide descrição mais adiante, no exame neurológico - limitamo-nos aqui a assinalar que a musculatura é normal á direita e apresenta algumas atrofias á esquerda. Esqueleto da mesma maneira assinalamos aquí somente a presença de uma cifoescoliose dorsal ligeira 'sendo o hemitorax direito maior que o esquerdo. Alem disso, o membro superior esquerdo é ligeiramente mais curto que o direito - vide exame neurológico. Mucosas visiveis bem coradas. Não ha ganglios palpaveis. Língua normal. Dentes: faltam os superiores onde em seu lugar foi feita uma prótese e os inferiores são falhados. Não ha caries visiveis nem raizes expostas.

\section{EXAME ESPECIAL}

Aparelho circulatório - A' inspecção não se notam edemas nem circulação colateral. Não ha batimentos epigástricos. Choque da ponta não visivel. Á palpação, percebe-se o choque da ponta ao nivel do $5 .^{\circ}$ intercosto esquerdo, um centimetro e meio para fora da linha mamilar. A' ausculta, as bulhas cardíacas são normais em todos os focos. Pressão arterial: 110-60. Pulso 110, ligeiramente taquicárdico, o que atribuimos á emotividade do doente. 
Aparelho respiratório - $A^{\prime}$ inspecção percebe-se alteração da dinâmica respiratória devido á assimetria do torax. A' palpação o frêmito tóraco-vocal é mais nítido á direita. Mobilidade normal dos ápices e bases pulmonares. A' percussão obtem-se som claro em todo o torax porem mais nitidamente á direita. A' ausculta, murmúrio vesicular normal em toda área pulmonar, embora tambem mais intenso á direita.

Aparelho digestivo - Nada notamos de anormal á inspecção, percussão e palpação do abdomen.

Aparelho endócrino - Tiroide normal. Distribuição dos pelos de tipo feminino na região pubiana. A inspecção nada se nota que indique alteração endócrina.

Aparelho genito-urinário - A' inspecção, os orgams genitais externos se apresentam de aspéto normal. Não ha pontos dolorosos reno-ureterais.

\section{EXAME NEUROLÓGICO}

Psiquismo aparentemente íntegro. Memória, atenção, afetividade e linguagem, dentro dos limites da normalidade. Bem orientado no espaço e no tempo. Cultura regular.

Equilíbrio normal; não ha o sinal de RoMBERG.

Atitude normal, quer na posição eréta, quer sentado ou em decúbito dorsal.

\section{Exame da motricidade:}

Motricidade voluntária - Executa perfeitamente todos os mor vimentos com a cabeça. Motricidade da face normal, não havendo sinal algum de paralisia facial. Nota-se porem que ha miose, enoftalmo e diminuição da rima palpebral - sindromo de Claude-BernardHorner — á esquerda. Nos membrós superiores, á direita, todos os movimentos são perfeitamente realizados. A esquerda, ha conservação de todos os movimentos voluntários das articulações escápulo-humeral, do cotovelo e punho, sendo nesta piesentes os movimentos de pronação, supinação, extensão e flexão. Nos dedos da nião é impossivel a realização voluntária de quaisquer dos movimentos de flexão, extensão, adução, abdução e oposição.

A's manobras de RAIMISTE e 'dos braços estendidos não notamos sinal algum de deficit muscular, embora para esta ultima o doente. não conseguisse manter os dedos do lado esquerdo em completa extensão, poís os mesmos estão sempre em atitude de semiflexão, que não se altera qualquer que seja a posição da mão.

Nos membros inferiores, notamos uma limitação ligeira de todos os movimentos do lado esquerdo, sendo or movimento de extensão do pé impossivel. E' perfeita a motricidade voluntária dos dedos dos 
pés. São impossiveis além disso os movimentos de rotação interna, rotação externa, adução e abdução do pé esquerdo.

Manobra de Mingazzini: revela deficit muscular á esquerda, tendo havido queda da perna sobre a coxa - deficit dos extensores da perna. A' manobra de BARRÉ não notamos nada de anormal no's seus 3 tempos.

Força muscular: Membros superiores: nos braços é normal e igual de ambos os lados. No antebraço ha uma diminuição das forças de flexão e extensão á esquerda. Na mão esquerda está abolidá a força muscular para qualquer movimento. No antebraço e mão direitos é normal a força muscular. Nos membros inferiores ha uma diminuição generalizada da força muscular á esquerda, sendo abolida apenas a força de flexão dorsal (extensão) do pé.

Coordenação dos movimentos bôa. A's manobras index-nariz, index-index e calcanhar-joelho, não se manifestam ataxias nem dismetrias. Não ha adiadococinesia, embora os movimentos da mão esquerda sejam prejudicados pela diminuição da força muscular e flacidês da mão.

Movimentação passiva - Tonus - A' palpação das massas musculares, ha uma hipotonia generalizada no membro superior esquerdo, mais acentuada no antebraço e mão. No membro inferior esquerdo ha certos músculos com ligeiro aumento do tonus em comparação com os do lado direito. Movimentos da. articulação do joelho esquerdo, mais limitados que á direita. Sinal do balanço passivo bem evidente no antebraço e especialmente na mão, do lado esquerdo.

Motricidade antomática - Fala, respiração e deglutição normaìs. Marcha ligeiramente ceifante e com arrastamento do pé esquerdo. Mímica normal.

Motricidade involuntária - Não ha movimentos espontaneos anormais. Motricidade reflexa: Reflexos profundos ósteo-tendinosos: normais em todo o hemicorpo direito. Do lado esquerdo ha exaltação dos reflexos médioplantar, patelar e aquilêo. Reflexo contra-lateral de Pierre-Marie exaltado á esquerda. Reflexo médiopubiano com resposta inferior viva á esquerda e normal á direita. No membro superior esquerdo são presentes os reflexos estilo-radial, e bicipital, que estão vivos. Reflexos tricipital e cúbito-pronador abolidos. Reflexo do omoplata exaltado á esquerda - sinal de NERI com 'nítida adução do membro superior. Reflexos naso-palpebral e oro-orbicular normais.

Reflexos superficiais - Abolidos os cutaneo-abdominais e cremastérico superficial á esquerda. Resposta supèrior do reflexo médiopubiano normal á direita e abolida á esquerda.

Reflexo cutaneo-plantar - invertido á esquerda - sinal de Babinski bem nítido, acompanhado de abertura em leque dos 4 últimos pedarticulos. Reflexos de Rossolimo e Mendel-Bechterew nítidos á esquerda. Variantes de Gordon, SchafER, OpPENHEIm presentes 
á esquerda. A' direita o reflexo cutaneo-plantar é normal. Reflexo de Rossolimo presente, nítido, á direita.

Reflexos pupilares á luz, acomodação e consensual, presentes e normais.

Clonus da rótula e do pé á esquerda.

Nã̃o ha automatismo ás manobras de $\mathrm{P}$ MARIE-Forx, BABINSKI e percussões repetidas.

Nãq ha sincinesias. mal.

Exame da sensibilidade: Sensibilidade superficial tactil nor-

Sensibilidade térmica alterada á esquerda, havendo termo-anestesia ao calor e ào frio na face interna do bráço, faces interná, anterior e posterior do antebraço e mão (vide esquema).

Sensibilidade dolorosa alterada - analgesia com a mesma distribuição da sensibilidade térmica (vide esquema).

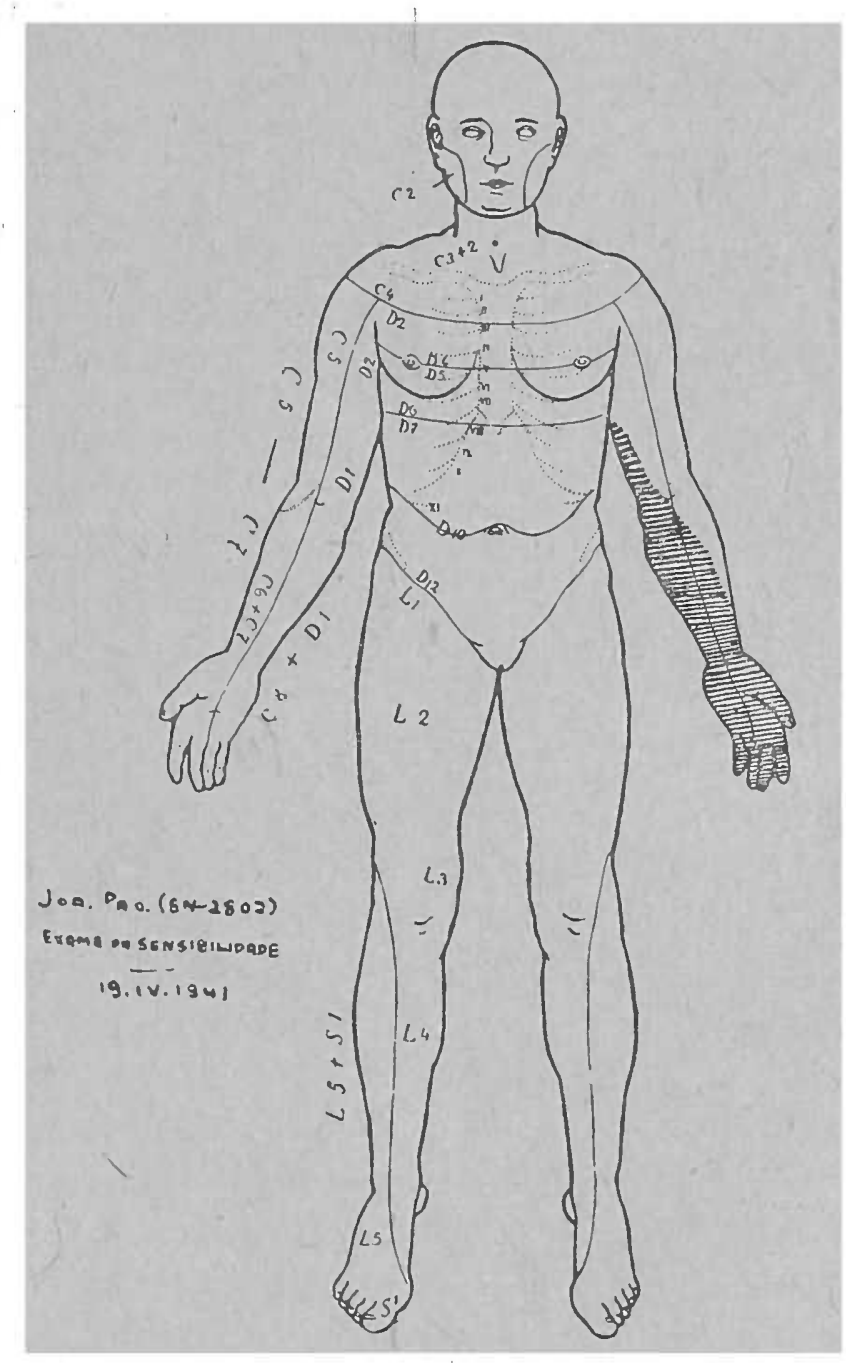

ANALGESA I TEQMOANESTES.A

Sensibilidade profunda - normal em todas as modalidades.

Fenômenos tróficos e vasculares - Esqueleto: Ha uma cifoescoliose ligeira da coluna vertebral, na região dorsal, com convexi- 


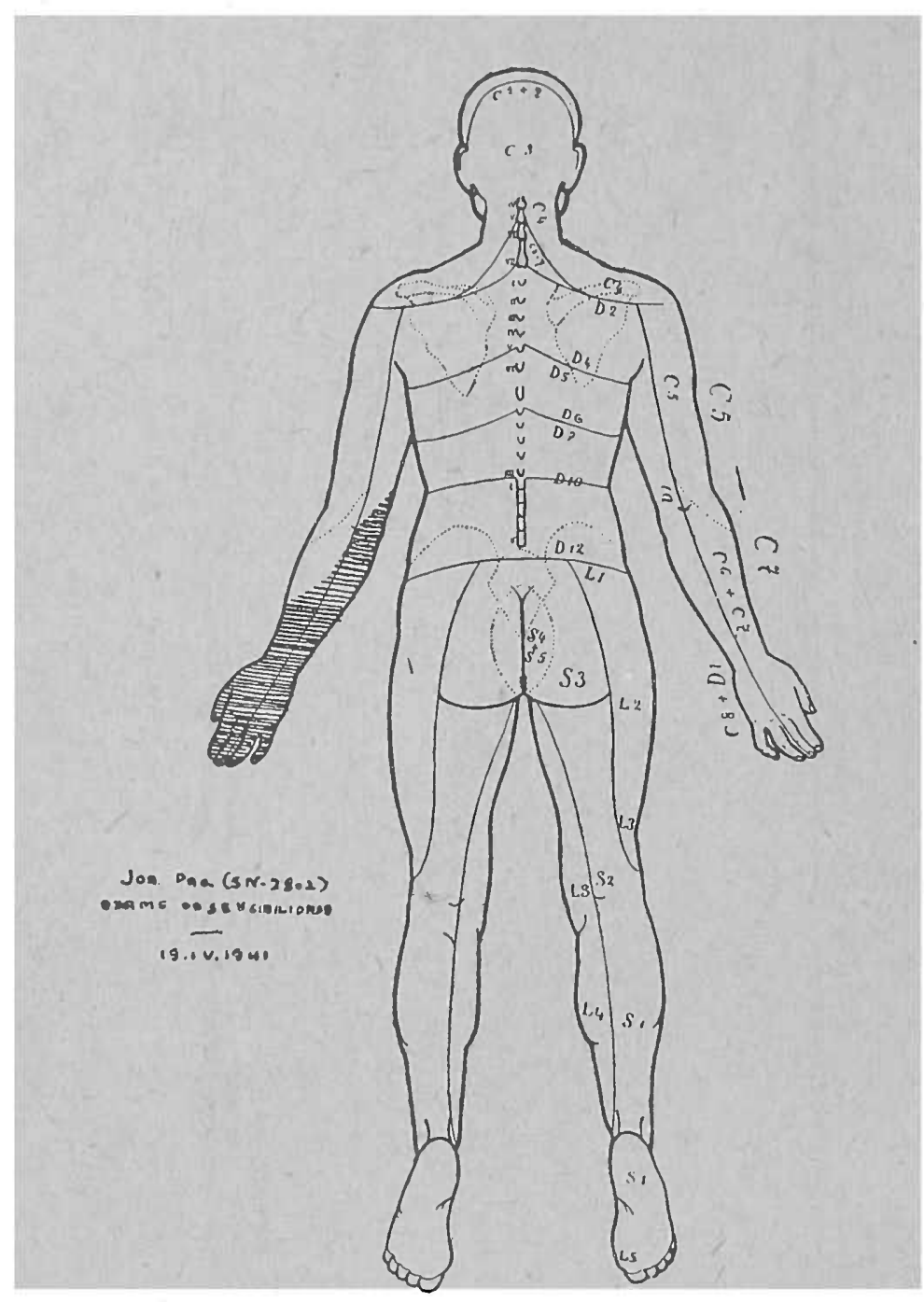

ANALGESIA. TERMORNESTESIR

dade para a esquerda desde D3 até $\mathrm{D} 8$ e convexidade para a direita desde D8 até L1. Como resultado da torsão vertebral produzida pela escoliose, ha uma deformação torácica, sendo o torax assimétrico e o hemitorax direito maior e mais saliente que o esquerdo.

A' inspecção do paciente nú, ha uma hemiatrofia generalizada do lado esquerdo do corpo, respeitando a face (figs. 1, 2 e 3 ). Essa atrofia é mais nítida no membro superior esquerdo. No antebraço esquerdo houve completo desaparecimento das massas musculares da região anterior e posterior. Mão com atrofia e hipotonia das eminencias tenar e hipotenar, havendo um achatamento das mesmas, realizando assim o tipo de mão simiesca - mão tipo DUCHENNE-ARAN - (fig. 4). Nos membros inferiores, ha tambem uma diminuição da espessura do lado esquerdo, verificando-se alem disso um abaixamento da rótula desse lado em relação ao direito. 


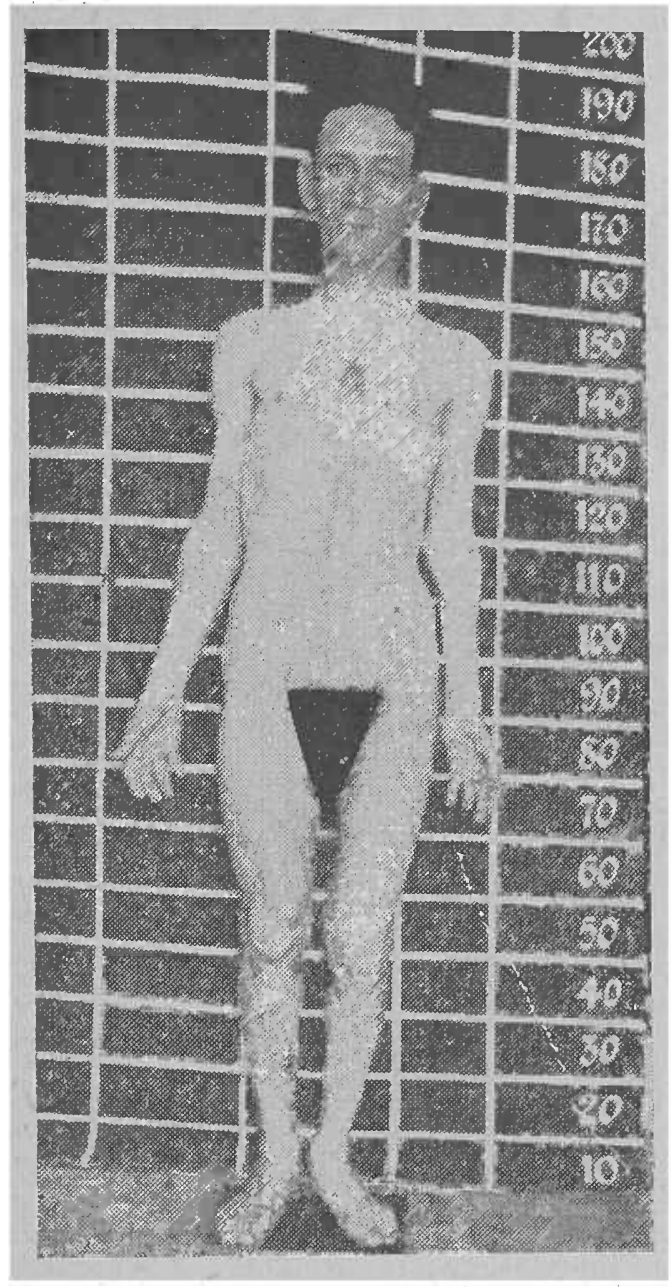

FIG. 1

Joa. Pag. (SN-2802) - Hemiatrofia corporal esquerda, respeitando a face. Vista anterior.

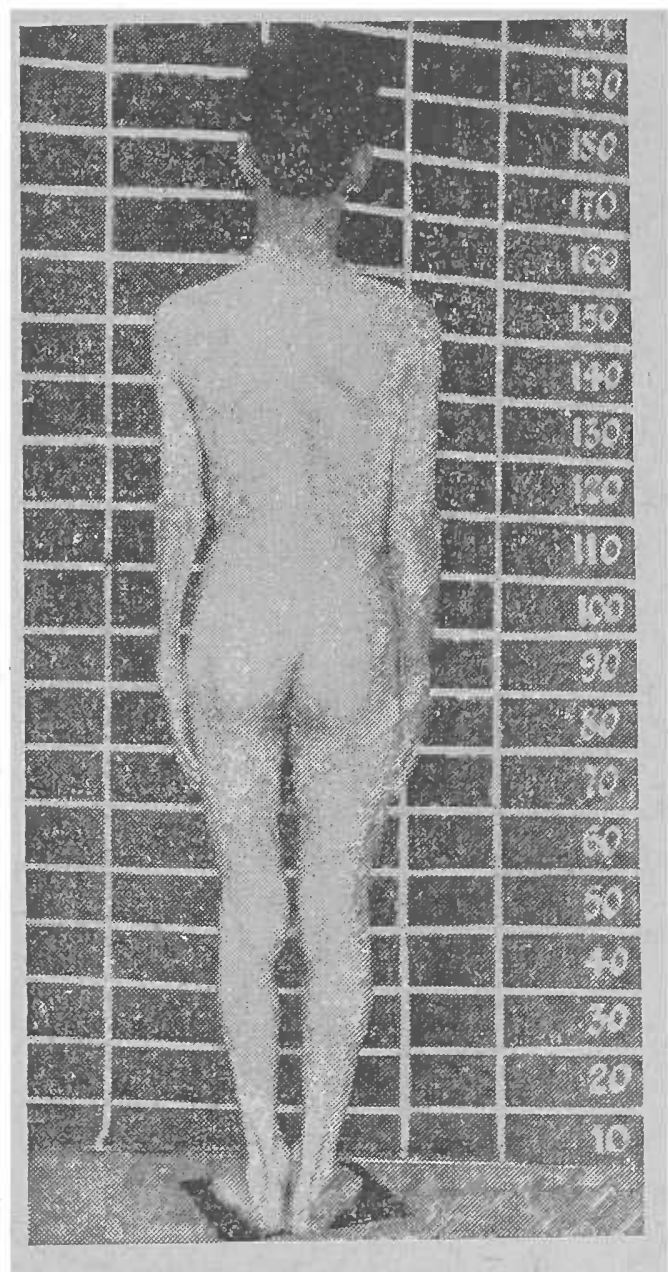

FIG. 2

jua. Pag. (SN-2802) - Hemiatrofia corporal esquerda. Vista posterior. Notar o maior comprimento do braço diretto $e$ as amiotrofias no antebraço esquerdo. 


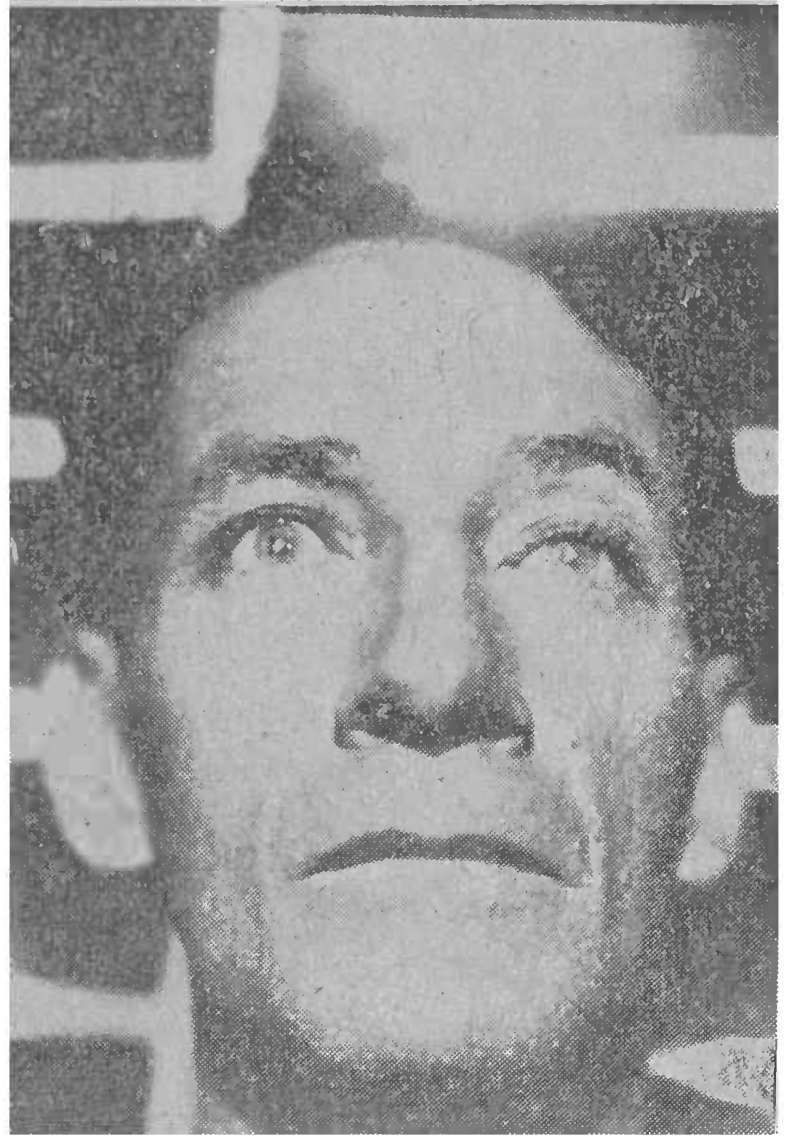

FIG. 3

Joa. Pag. (SN-2802) - Vista da face. Notar a queda da palpebra e anisocoria com miose á esquerda.

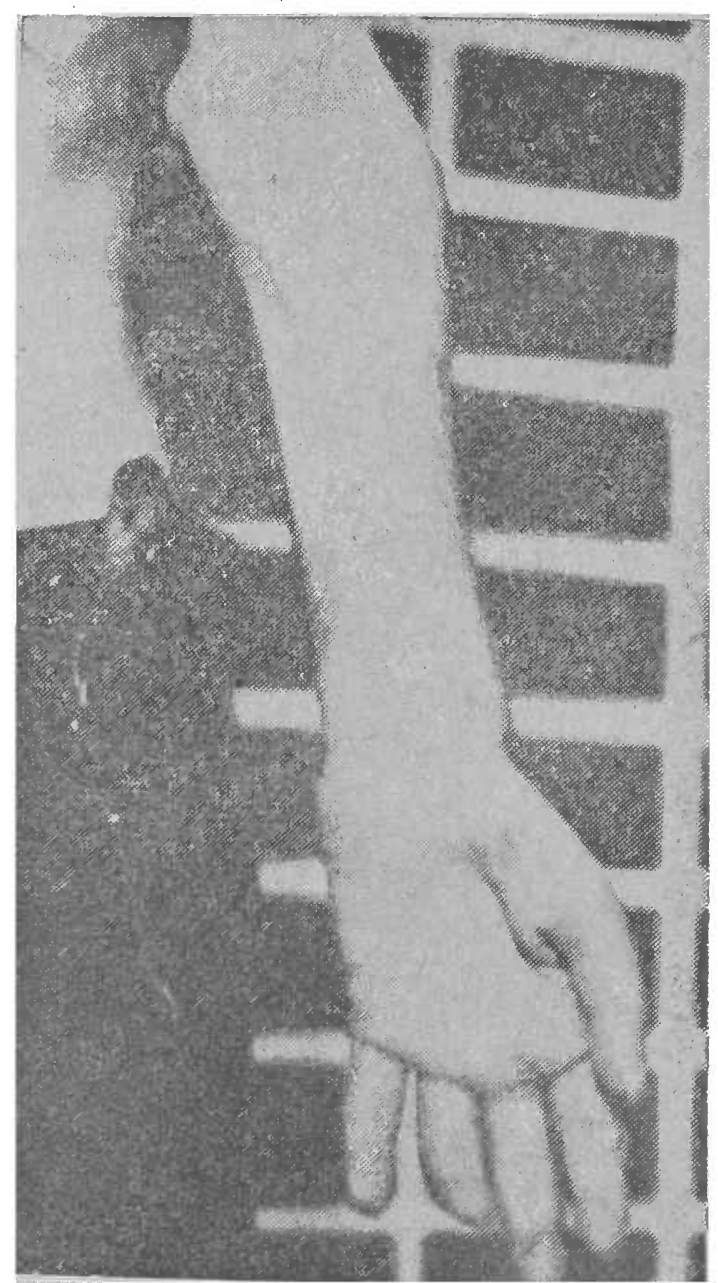

FIG. '4

Joa. Pag. (SN-2802) - Vista do antebraço e mâo esquerdos. Amiotrofias tipo Aran-Duchenne. Mão simiesca. 


\section{EXAMES COMPLEMENTARES}

Reação de Wassermann no sangue: negativa.

Exame-neuro-ocular: Sindromo de C1. Bernard-Horner esquerdo. Ambliopia (ex non usu?) esquerda.

(Dr. Durval Prado)

O electro-diagnostico mostrou em conclusão o seguinte:

Os pontos neuro-motores pesquizados (ponto de Erb, n. radial, n. cubital e mediano no cotovelo, n. cubital no punho), com excepção do n. mediano no punho (inexcitavel), respondem com intensidade galvânica normal; a resposta, no entanto, é apenas de alguns músculos dos respectivos territórios.

Pontos mio-motores - do deltoide, biceps, respondem normalmente.

- Pontos mio-motores - do território do n. radial: - os músculos longo supinador e radiais externos estão normais; os extensor comum dos dedos, extensor próprio do index, longo abdutor do polegar são inexcitaveis com 30 MA.

Território do n. mediano - feixe externo do $\mathrm{m}$. flexor comum dos dedos e pequeno palmar são inexcitaveis.

Territorio do nervo mediano no punho (Inexcitavel) - $\mathrm{m}$. curto abdutor do polegar, oponente do polegar são inexcitaveis (RD cadavérica).

Território do cubital (cotovelo) - feixe interno do flexor comum dos dedos responde normalmente; cubital anterior inexcitavel.

Território do cubital (punho) - M. interosseos dorsais são inexcitaveis; $m$. adutor do polegar reage com 16 MA. em C. L. Os restantes estão normais.

Os músculos da cintura escapular e membros inferiores reagem normalmente ao excitante galvânico.

As alterações encontradas pelo exame elétrico são características das lesões das células motoras dos cornos anteriores da medula.

(Dr. Carlos V. Savoy)

\section{SÚMULA}

Resumindo a observação que fizemos, obtivemos os seguintes dadós positivos, de interesse para a orientação do diagnóstico do caso em apreço:

1. ${ }^{\circ}$ Em nosso paciente instalou-se subitamente ha 30 anos uma tetraplegia sem perda da cònciência nem da fala; essa tetraplegia melhorou lentamente, atingindo as melhoras, 2 anos depois, um estado com o qual se apresenta até hoje;

2. $\left.{ }^{\circ}\right) \mathrm{Ha}$ hemiparesia á esquerda, verificavel pelos seguintes sinais :

a) paralisia de todos os movimentos da mão; 
b) diminuição da força muscular no antebraço e na mão, abolição da força muscular nos dedos;

c) limitação ligeira dos movimentos voluntários do membro inferior ;

d) paralisia da extensão, rotação interna, rotação externa, adução e abdução do pé;

e) deficit muscular dos extensores da perna, verificavel pela manobra de Mingazzini.

f) diminuição generalizada e ligeira da força muscular no membro inferior;

$3^{\left.3^{\circ}\right)}$ Sindromo óculo-simpático d'e Claude Bernard-Homer á esquerda;

4..$^{\circ}$ Hipotonia muscular no membro superior esquerdo;

5..$^{\circ}$ Ligeira hipertonia muscular no membro inferior esquerdo;

6. ) Marcha ligeiramente ceifante á esquerda;

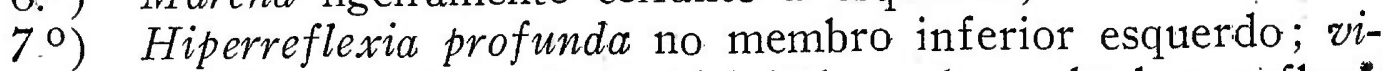
vacidade dos reflexos estilo-radial e bicipital, sendo exaltado o reflexo do omoplata, tambem á esquerda;

8. ) Abolição dos reflexos cúbito-pronador e tricipital á esquerda;

9..$^{\circ}$ Sinal de Babinski e variantes presentes á esquerda. Sinais de Rossolimo e Menóel-Bechtereíw á esquerda. Sinal de RossoLIMO á direita.

10..$^{\circ}$ Termo-anestesia e analgesia, com conservação da sensibilidade tactil (dissociação siringo-miélica) no's territórios cutaneos dependentes das raizes C6 - C7 - C8 e D1.

11. ${ }^{\circ}$ ). Perturbações tróficas vertebrais e torácicas - cifoescoliose e assimetria torácica.

12. ${ }^{\circ}$. Amiotrofias no antebraço e mão esquerdos - tipo Duchenne-Aran.

13..$^{\circ}$ Síndromo elétrico de degenérescencia nos seguintes músculos: extensor comum dos dedos, extensor próprio do index, longo abdutor do polegar, feixe interno do flexor comum dos dedos, pequeno palmar, curto abdutor do polegar, oponente do polegar, cubital anterior, interosseos dorsais e adutor do polegar; caracterizando lesões dos cornos anteriores da medula.

Antes de discutir os vários sintomas apresentados pelo doente para tentar o diagnóstico lesional e topográfico, parece-nos util confrontar os resultados dos dois exames neurológicos, feitos ambos neste Serviço, um em 1936 e outro agora, em 1941. Existem nestas duas' observações alguns fátos discordantes.

Realmente, foram assinalados em 1936 alguns sintomas que na realidade não existem, ao passo que nãc foram verificados alguns outros que, ao nosso vêr, têm primacial importancia para a discussão diagnóstica.

Entre os primeiros estão a hemiațrofia facial esquerda e a hipoexcitabilidade dos músculos da face; entre os segundos estão a disso- 
ciação siringomiélica da sensibilidade no território correspondente a C6, C7, C8 e D1, e o síndromo de Claude Bernard-Horner á esquerda. A inexistencia da hemiatrofia facial esquerda - em 1936 ela foi descrita com abundancia de pormenores (vide observação) - está bem documentada na fotografia anexa (vide fig. 3) tirada em Abril de 1941. As duas hemifaces são identicas; não ha desvio da rima labial e do sulco naso-genianó, não ha maior saliência da região malar á esquerda. O que existe é uma diminuição da rima palpebral assinalada já na observação de 1936 - porem erradamente interpretada naquela ocasião; esse estreitamento da fenda palpebral não é secundário á hemiatrofia facial e sim elemento componente do sindromo de Claude Bernard-Horner.

A hipoexcitabilidade elétrica dos músqulos da face - tambem relatada na observação de 1936, embora já tivesse sido admitida com reservas pois todos os músculos faciais reagiram com excitações menores de $10 \mathrm{MA}$ - não foi confirmada no exame procedido em 1941.

Por outro lado, na observação feita em 1936, não foram assinalados dois elementos de grande importancia: o síndromo de Claude BERNARD-Horner $e$ a dissociação siringomiélica da sensibilidade.

O sinidromo de Claude Bernard-HForner apresentado pelo doente é completo - enoftalmo, miose e estreitamento da fenda palpebral' - e já existia em 1936, porquanto naquela ocásião foram assinalados a anisocoria com miose e a diminuição da rima palpebral, tudo á esquerda. O que se deu, evidentemente, for que o neurologista, em 1936, não reuniu os dados em um conjunto síndrômico e não teve sua atenção dirigida para a possivel existencia do síndromo óculo-simpático.

A dissociação siringomiélica da sensibilidade nos territórios inervados pelos $6 .^{\circ}, 7 .^{\circ}, 8 .^{\circ}$ segmentos cervicais e $1 .^{\circ}$ dorsal, constitue o elemento mais importante encontrado agora pois que êle, por si só, justifica a modificação do diagnóstico do caso e permite uma localização exáta da lesão.

Ha ainda outro elemento que for assinalado em 1936 e não foi encontrado em 1941: referimo-nos aos tremores fibrilares nos músculos da cintura escapular. Sem querer pôr em dúvida o cuidado com que foi feita a observação anterior, não nos é possivel compreender que estes tremores tenham desaparecido integralmente e, o que é mais interessante, sem deixar reliquats. E' sabido que os tremores fibrilares indicam o sofrimento das células dos cornos anteriores da medula: portanto si, em 1936, existiam tremores fibrilares nos músculos da cintura escapular, era lógico esperar que hoje, nestes músculos existissem anormalidades no que diz respeito á excitabilidade elétrica e troficidade. Ora, o electrodiagnóstico, procedido em 1941, mostrou estar normal o limiar de excitabilidade destes músculos. Seria mais razoavel que tais tremores existissem, naquela ocasião, nos músculos do antebraço onde existem extensas atrofias; no entanto tais perturbações não foram assinaladas. E' verdade que o doente foi submetido, desde 1936 a esta data, a intenso tratamento radioterápico visando a coluna cervical: é possivel que a evolução do processo poliomie- 
lítico tivesse sido interrompida por essa medicação e consequentemente, tivessem desaparecido os tremores fibrilares - tradução clínica dessas lesões progressivas. A julgar pelas expressões do paciente, porem, o processo mórbido está absolutamente éstacionado, não desde 1936, porem desde 1912 e as mesmas atrofias que apresenta agora já existiam muito anteriormente ao exame neurológico procedido em 1936.

$$
\text { * * * }
$$

Este estudo comparativo entre as duas observações nos pareceu indispensavel pois, dadas as alterações neurológicas que encontramos no doente, não podemos confirmar o diagnóstico de esclerose lateral amiotrófica que fôra feito anteriormente. O modo de início da molestia (ictus), a redução da sintomatologia inicial - tetraplegia para hemiparesia no periodo de estado, existencia do síndromo de Claude Bernard-Horner, da zona de dissociação siringomiélica da sensibilidade e as deformações esqueleticas unilaterais, e, finalmente o estacionamento completo, da molestia ha mais de 20 anos, infirmam esse diagnóstico. E' bem 'verdade que, em 1936, o diagnóstico de esclerose lateral amiotrófica não fôra feito com facilidade, tanto assim que o neurologista fôra obrigado a encaixar o caso dentro dos limites nosográficos de uma forma anômala e muito rara da moléstia - esclerose lateral amiotrófica - forma hemiplégica, apopletiforme.

A sintomatologia neurológica apresentada por Joa. Pag. não se explica tão sómente pelas lesões sistematizadas de esclerose amiotrófica. Não ha dúvida que existem lesões no corno anterior e no feixe piramidal: a lesão do corno anterior explica a atrofia de tipo DuCHENE-ARAn e o síndromo de degenerescencia nos músculos da mão e do antebraço; a existencia da lesão piramidal é confírmada pela hipertonia em extensão do membro inferior, pela hiperrefletividade profunda, pelos sinais de Babinski, MENdel-Bechterew e Rossolimo, pela presença do clonus, pelo tipo de marcha e pelo deficit na força muscular ná realização de movimentos voluntários. A hemiatrofia generalizada, verificavel no hemicorpo esquerdo é atribuivel á falta das incitações motoras piramidais e consequentemente á falta de função, deficit este que se estabeleceu ha 30 anos, tempo suficiente para justificar a assimetria corporal.

Mas ha a considerar ainda o síndromo de ClAUde BERNARDHorner e a dissociação siringomiélica da sensibilidade. Ambos, sómente poderão ser explicados pela lesão do segmento médio da medula : as fibras condutoras da sensibilidade termo-dolorosa, fibras curtas, seriam lesadas no seu trajéto pela substancia cinzenta intermediaria entre os cornos anterior e posterior; o síndromo óculo-simpático de Claude Bernard-Horner seria a tradução clínica da lesão do centro cilio-espinhal de BUDGE, coluna de células vegetativas disposta na. substancia intermédio-lateral.

Não se trata de uma lesão sistematizada e eletiva pois a dissociação siringomiélica assume, no caso, uma disposição isomera em relação aos segmentos medulares lesados e, desde que esta perturbação da sensibilidade atinge os territórios inervados pelos $60^{\circ}, 7{ }^{\circ}, 80^{\circ}$ 
seginentos cervicais e $1 .^{\circ}$ dorsal, é este o distúrbio que marca a localização vertical do processo mórbido. Confirma-se esta localização da lesão se atentarmos para a distribuição dos distúrbios á excitação elétrica, para a.localização das amiotrofias e pará as modificações dos átos reflexos (abolidos os reflexos cubito-pronador e tricipital).

Todos estes fátos indicam que, na região cervical, desde C6 até D1, exste uma lesão da substancia cinzenta; o síndromo de ClaUde Bernard-Horner, já o dissemos, depõe no meśmo sentido.

Não estamos pois em presença de um caso de esclerose lateral amiotrófica. Nesta molestia como é sabido, existe uma lesão do corno anterior e do feixe piramidal: estas lesões nunca produzem uma dissociação siringomiélica da sensibilidade nem o síndromo de Claude Bernard-Horner.

A lésão é portanto mais extensa, abrangendo o corno anterior, a substancia cinzenta, a coluna intermédio-lateral e o feixe piramidal, localizada na hemi-medula esquerda, e compreendida entre C6 e D1. Sua localização, deve obedecer ao seguinte esquema:

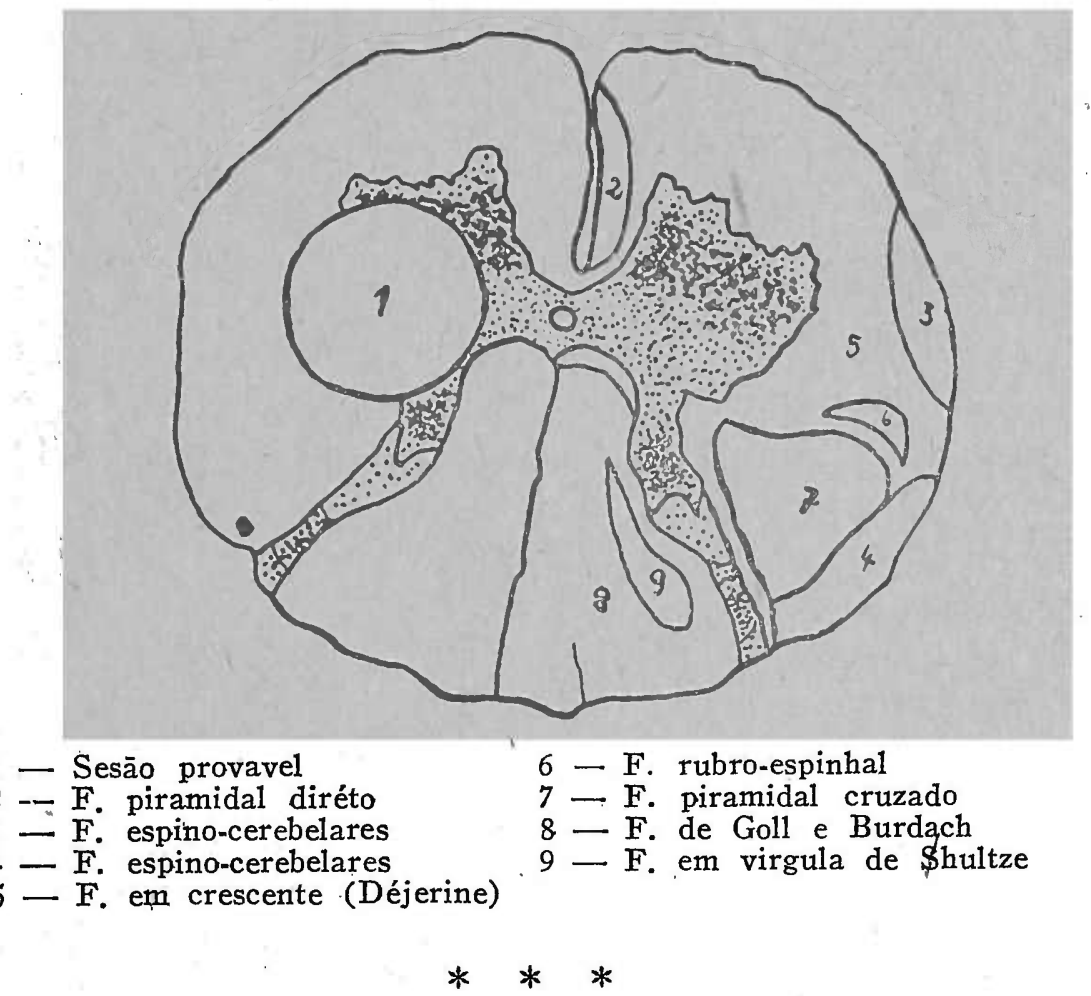

O diagnóstico de esclerose lateral amiotrófica porderia ser discutido desde logo, si nos houvessemos baseado no modo de inicio e na evolução da molestia.

Realmente, a esclerose lateral amiotrófica é uma molestia sistematizada da medula, que tem geralmente inicio lento, raramente brusco, apresenta uma evolução lentamente progressiva que leva á morte na maior parte das vezes, sendo de notar aquí que durante todo o decorrer da molestia persistem no doente os tremores, fibrilares que desapareceram no nosso caso. A presença de perturbações dependentes de lesão bulbar é outro caráter da esclerose lateral amiotrófica, que não existe no nosso doente. 
Alem dissc a molestia tem sintomatologia bilateral. ligado á sistematização bilate:al, das lesões medulares. Mesmo nas chamadas formas hemiplégicas, ha sempre alguns sinais neurológicos do lado oposto do corpo, indicando a bilateralidade das lesões. E' verdade que no caso que estudamos, encontramos á direita um sinal de Rossolimo muita nítido. Porem este sinal, desacompanhado de qualquer outro sintoma piramidal ou poliomielítico, não tem, a nosso ver, um valor incontestavel. Por outro lado, a lesão unilateral da hemimedula esquerda, caso ela se propagasse um pouco mais para a frente, poderia atingir as fibras até então dirétas do feixe piramidal de TÜrCK que se destinam aos membros inferiores: é possivel que essa lesão pudesse ser responsabilisada pelo aparecimento do sinal de Rossolimo á direita.

O modo de início da molestia apresentado por Joa. Pag. - ictus apoplectiforme sem perda do conhecimento e com tetraplegia flácida reduzida depois á hemiplegia esquerda - leva a pensar em um processo vascular, amolecimento ou hematomielia. Mais provavel é a hematomielia, dada a extensão da zona lesada. O amolecimento produziria sintomatologia neurológica mais reduzida, mais focalizada. Ao contrário, uma hemorragia intra-medular, seja por compressão ou por dilaceração, poderia produzir uma lesão mais extensa tanto em largura como em altura.

A anamnese do caso não forneceu qualquer indício a respeito da etiologia do processo. $O$ doente não relata traumatismo raquidiano ou qualquer processo tóxico-infeccioso, que pudesse ser responsabilizado pela hematomielia. E' verdade que suas informações, dada sua pouca idade na ocasião do acidente neurológico inicial, não permitem uma precisão absoluta nesse sentido. Tais fátos negativos nos cbrigam a admitir a possibilidade de uma hematomielia espontanea. A tetraplegia inicial seria explicada pelo edema medular difuso que acompanhou a hemorragia focal.

Só este diagnóstico, a nosso ver, justifica o modo de início brusco (ictus), a regressão paulatina da tetraplegia (desaparecimento do edema medular), e, or que é mais importante a parada cornpleta da evolução da moléstia desde que ela atingiu o período de estado. Não encontramos, na história do caso por nós estudảdo nem a evolução contínua, característica da esclerose lateral amiotrófica, nem a evolução por etapas da siringomielia e da gliose medular progressiva. A fixidês da sintomatologia neurológica é um detalhe importante sobre o qual as afirmativas do doente são peremptórias.

E essa fixidês da sintomatologia excluindo, alem da esclerose lateral amiotrofica, da siringomielia e gliose medular progressiva, tambem os tumores intra e extra-medulares, nos leva a reafirmar que Joa. Pag. sofreu uma hematomielia espontanea que destruiu definitivamente uma parte da hemimedula esquerda, compreendida entre C6 e D1, lesão esta responsavel por toda a sintomatologia que o doente apresenta. 